\title{
High Temperature Flexural Deformation Properties of Engineered Cementitious Composites (ECC) with Hybrid Fiber Reinforcement
}

\author{
Zhihui YU ${ }^{1}$, Zhen YUAN ${ }^{1}$, Chaofan XIA ${ }^{1}$, Cong ZHANG ${ }^{1,2 *}$ \\ 1 Advanced Fiber Reinforced Cementitious Composites Lab, Jiangnan University, School of Environmental and Civil Engineering, Wuxi, \\ 214000, China \\ 2 State Key Laboratory of Green Building Materials, Beijing, 100024, China
}

*Corresponding Author: Cong ZHANG, Email: zhangcong@jiangnan.edu.cn

\begin{abstract}
:
Engineered Cementitious Composites (ECC) is a class of high-performance fiber reinforced composites with ultra-ductility designed based on micromechanics, and it has been developed for increasing application in the construction industry during recent decades. The properties of ECC at room temperature have been tested and studied in depth, however, few studies focus on its performance after high temperature that is one of the worst conditions to ECC. To investigate the change tendency and mechanism for the high temperature flexural properties of hybrid fiber reinforced ECC and the feasibility of calcium carbonate whisker to reduce the cost of ECC materials, polyvinyl alcohol fiber (PVA) reinforced strain hardening cementitious composites (PVA-ECC), steel fiber + PVA fiber reinforced ECC (defined as HyFRECC-A) and steel fiber + PVA fiber $+\mathrm{CaCO}_{3}$ whisker reinforced ECC (defined as HyFRECC-B) subject to room temperature and $200{ }^{\circ} \mathrm{C}, 400{ }^{\circ} \mathrm{C}, 600{ }^{\circ} \mathrm{C}, 800{ }^{\circ} \mathrm{C}$ elevated temperature exposure were experimentally compared. The results indicate that equally replacing PVA fibers by steel fibers degraded the flexural hardening ability of PVA-ECC at room temperature, while the addition of appropriate amount of $\mathrm{CaCO}_{3}$ whisker improved the flexural strength, toughness and flexural hardening behavior. The elevated temperature posed a significant effect on the flexural strength and toughness of the three types of ECCs. Flexural deflection hardening behavior of the three types of ECCs was eliminated after high temperature exposure. Flexural strength and toughness of PVA-ECC presented an exponential decay along with the increase of temperature. The addition of steel fiber slowed down the decay rate. Although the use of $\mathrm{CaCO}_{3}$ whisker increased the post-temperature flexural strength and toughness of HyFRECC-B, the decay rate was not further decreased.
\end{abstract}

Keywords: engineered cementitious composites; hybrid fiber; high temperature; flexural behavior

\section{Introduction}

Based on fracture mechanics and micromechanics, Engineered Cementitious Composite (ECC) designed by adjusting fiber, matrix and interfacial properties of fiber/ matrix significantly improved the inherent high brittleness and low toughness of cementitious materials ${ }^{[1-3]}$. ECC is a type of composite materials with high ultimate tensile strain (usually exceeds 1\%) and obvious multiple crack cracking characteristics which makes it increasingly used in civil engineering, such as structural strengthening, Beamcolumn joints, lining tunnel and so on ${ }^{[4,5]}$. However, the high cost of ECC has always been an engineering dilemma. The subject of application of ECC in construction consists of a set of problems that are central to effectively reduce the cost of it.

It is generally accepted that fiber blending is one of the most important methods to reduce the cost of ECC so far ${ }^{[6-8]}$. The mix proportion and fundamental properties of hybrid fiber ECC materials (HyFRECC), which was added to fibers with different elastic modulus, was studied by domestic and foreign scholars in recent years. And based on the performance price ratio consideration, currently the attention of academic community and engineering community focus on steel fiber + PVA fiber reinforced ECC (HyFRECC-A). The tensile property, flexural property and anti-impact property of HyFRECC-A were investigated by scholars like Khin ${ }^{[9,10]}$, Alessandro ${ }^{[11]}$, Zhang ${ }^{[12]}, \mathrm{Xu}^{[13]}$, etc. However, it must be emphasized that high temperature is one of the most adverse conditions that ECC may encounter in service ${ }^{[14,15]}$. To date, several experimental studies conducted by Mechtcherine ${ }^{[16]}$, Bhat ${ }^{[17]}$, Magalhaes ${ }^{[18]}$ and $\operatorname{Lin}^{[3]}$ show that the tensile property of PVA-ECC is obviously degraded by high temperature. Especially when 
the temperature exceeds $150{ }^{\circ} \mathrm{C}$, PVA-ECC starts to lose its ductility. ECC loses almost all of its strain hardening characteristics and multi-slit cracking behavior due to PVA fiber, which is used to confect ECC widely up to now, would be melting and failure completely at $250{ }^{\circ} \mathrm{C}$. However, limited effective investigations have been conducted to study the high-temperature behavior of steel fiber + PVA fiber reinforced ECC (HyFRECC-A). In terms of research findings of the high-temperature behavior of steel fiber reinforced concrete, the incorporation of steel fiber can effectively improve the basic mechanical properties of concrete after high temperature action. But the effect of steel fiber on the mechanical properties of PVA-ECC after high temperature is not clear at present, that's why it remains to be further explored.

Based on previous research results ${ }^{[19-21]}$, the primary aim of this paper is to critically analyze the effects of cheap $\mathrm{CaCO}_{3}$ whisker on the properties of ECC materials. In order to further reduce the cost of hybrid fiber ECC materials, steel fiber + PVA fiber $+\mathrm{CaCO}_{3}$ whisker reinforced ECC (HyFRECC-B) was fabricated in our group. Then the flexural tensile properties of PVA-ECC, HyFRECC-A and HyFRECC-B at room temperature and after $200^{\circ} \mathrm{C}$, $400{ }^{\circ} \mathrm{C}, 600{ }^{\circ} \mathrm{C}, 800{ }^{\circ} \mathrm{C}$ elevated temperature exposure were experimental compared.

\section{Test Materials and Methods}

\subsection{Matrix}

Cement mortar matrix was selected, which contains $\mathrm{P}=\mathrm{O} 42.5$ cement, fly ash, fine quartz sand (particle size $100 \sim 210 \mu \mathrm{m}$, mean size $150 \mu \mathrm{m}$ ) and mixed according to cement, fly ash, quartz sand =1:4:1.8 ratio, water-binder ratio is 0.34 . Polycarboxylic acid superplasticizer (water reduction rate $28.3 \%$ ) and plasticizer (thickening type) were used to adjust the workability of fresh mortar. Table. 1 shows the mass fraction of each mixture in the matrix.

\subsection{Fibers}

Steel fiber and $\mathrm{CaCO}_{3}$ whisker were employed as the extra fibers of conventional ECC and the key point in the experimental study. Steel fiber selected from Shanghai Zhen Qiang Fiber Limited Company has end hooks. The melting point of PVA fiber selected from Japan kuraray Company is $244^{\circ} \mathrm{C} \sim 250{ }^{\circ} \mathrm{C}$. The decomposition temperature of $\mathrm{CaCO}_{3}$ whisker selected from Shanghai Feng Zhu Whisker Limited Company is $780{ }^{\circ} \mathrm{C}$. Table. 2 lists the main parameter of fibers. From the table. 2, it can be seen that the price of $\mathrm{CaCO}_{3}$ whisker and steel fiber is much cheaper than PVA, but both the tensile strength and elastic modulus of the other two fibers are much higher compared with PVA. In addition, $\mathrm{CaCO}_{3}$ whisker, belonging to microfibers, provides effective reinforcement at the micro cracking level, restrain the generation and coalescence of micro cracks into unstable macro cracks, and bring great improvement of strength.

Up to now, common fiber volume dosage of HyFRECC-A in study on performance at room temperature is steel fiber $0.25 \%$, PVA fiber $1.75 \%$. Based on this dosage and combined with the previous research results, $\mathrm{CaCO}_{3}$ whisker was added to confect HyFRECC-B. Previous research results ${ }^{[19-21]}$ indicate that $\mathrm{CaCO}_{3}$ whisker can improve the microstructure and fracture morphology of HYFRECC-A matrix by means of crack deflection, bridging and whisker pull-out. So as to improve the tensile strain hardening ability and multi-crack cracking ability of HYFRECC-A material, and further reduce the cost of HYFRECC-A by replacing PVA fiber with $\mathrm{CaCO}_{3}$ whisker appropriately. Volume fraction of different fibers are listed in Table. 3.

Table 1 Mass fraction of each mixture

\begin{tabular}{cccc}
\hline $\begin{array}{c}\text { Powder } \\
(\text { Cement }+ \text { Fly ash }+ \text { Sand })\end{array}$ & Water & Water reducer & Plasticizer \\
\hline 1 & 0.248 & $2.62 \times 10^{-3}$ & $4.52 \times 10^{-4}$ \\
\hline
\end{tabular}

Table 2 The main parameters of fibers

\begin{tabular}{|c|c|c|c|c|c|c|}
\hline Types & Length/mm & Diameter $/ \mu \mathrm{m}$ & $\begin{array}{c}\text { Tensile strength/ } \\
\mathrm{MPa}\end{array}$ & $\begin{array}{l}\text { Elastic modulus/ } \\
\qquad \mathrm{GPa}\end{array}$ & $\begin{array}{c}\text { Density/ }(\mathrm{g} / \\
\left.\mathrm{cm}^{3}\right)\end{array}$ & $\begin{array}{c}\text { Price/ } \\
\text { (thousand } \\
\text { yuan/ton) }\end{array}$ \\
\hline steel fiber & 13 & 200 & 2000 & $200 \sim 210$ & 7.8 & 20 \\
\hline PVA fiber & 12 & 39 & 1100 & 42.8 & 1.3 & 140 \\
\hline $\mathrm{CaCO}_{3}$ whisker & $0.02 \sim 0.03$ & $0.5 \sim 1$ & $3000 \sim 6000$ & $410 \sim 710$ & 2.8 & 1.5 \\
\hline
\end{tabular}

Table 3 Volume fraction of different fibers

\begin{tabular}{cccccc}
\hline Types & Groups & Steel fiber $\%$ & PVA fiber/\% & $\begin{array}{c}\mathrm{CaCO}_{3} \\
\text { whisker/\% }\end{array}$ & $\begin{array}{c}\text { Compressive } \\
\text { strength } / \mathrm{MPa}\end{array}$ \\
\hline PVA-ECC & PVA2 & 0 & 2 & 0 & 41.7 \\
HyFRECC-A & SF0.25PVA1.75 & 0.25 & 1.75 & 0 & 46.0 \\
HyFRECC-B & SF0.25PVA1.7CW0.5 & 0.25 & 1.7 & 0.5 & 50.8 \\
& SF0.25PVA1.65CW1 & 0.25 & 1.65 & 1 & 53.2 \\
\hline
\end{tabular}




\subsection{Specimen details}

With reference to ISO $679^{[22]}$, the mixed materials were put into standard cement curing box (Temperature: $20 \pm 2{ }^{\circ} \mathrm{C}$, humidity: $95 \%$ ) for $24 \mathrm{~h}$ after they were formed, then take the specimen out of the mold and put it into the curing box for 28d. Finally, the specimens were removed and placed in an oven at $105{ }^{\circ} \mathrm{C}$ for drying to a constant weight followed by high-temperature test. With reference to ASTM C348 $8^{[23]}$, ASTM C1609 $9^{[24]}$ and JCI-SF4 ${ }^{[25]}$, the specimens with the dimension of $40 \mathrm{~mm} \times 40 \mathrm{~mm} \times 160$ $\mathrm{mm}$ were tested to investigate the flexural behaviors. Each group has 15 proportioned specimens, which are used for flexural mechanical properties test under five temperature conditions. The preparation process of specimens adopted in the test are shown in figure 1.

\subsection{High-temperature test}

SX-10-12 box type resistance furnace was used to provide a high temperature environment. During the forming process of the specimens, WRNK-191 probe thermocouple was embedded and XMZ-101 temperature instrument was connected externally to monitor the temperature change in the center of the specimen to determine the difference between the internal temperature of the specimen and the ambient temperature of the resistance furnace. Figure 2 shows the high temperature instrument.

The heating program is shown in figure 3 , the heating rate is $10{ }^{\circ} \mathrm{C} / \mathrm{min}$. Five temperature conditions (room temperature $20{ }^{\circ} \mathrm{C}, 200{ }^{\circ} \mathrm{C}, 400{ }^{\circ} \mathrm{C}, 600{ }^{\circ} \mathrm{C}$ and $800{ }^{\circ} \mathrm{C}$ ) were designed totally. In order to make the temperature inside and outside the specimen uniform, the temperature was maintained for 60 min under each high-temperature working condition. The specimens, which were naturally cooled to room temperature, were tested to investigate the flexural behaviors after high temperature action.

\subsection{Loading configuration}

Each specimen was loaded under four-point flexural by MTS E44 electronic universal testing machine with a span of $120 \mathrm{~mm}$ between supports. Load transducer and clip type extensometer were employed to monitor the relationship between flexural load and mid-span deflection of specimen. Displacement loading control was adopted, and the loading rate was $0.1 \mathrm{~mm} / \mathrm{min}$. The loading configuration is shown in figure 4 .

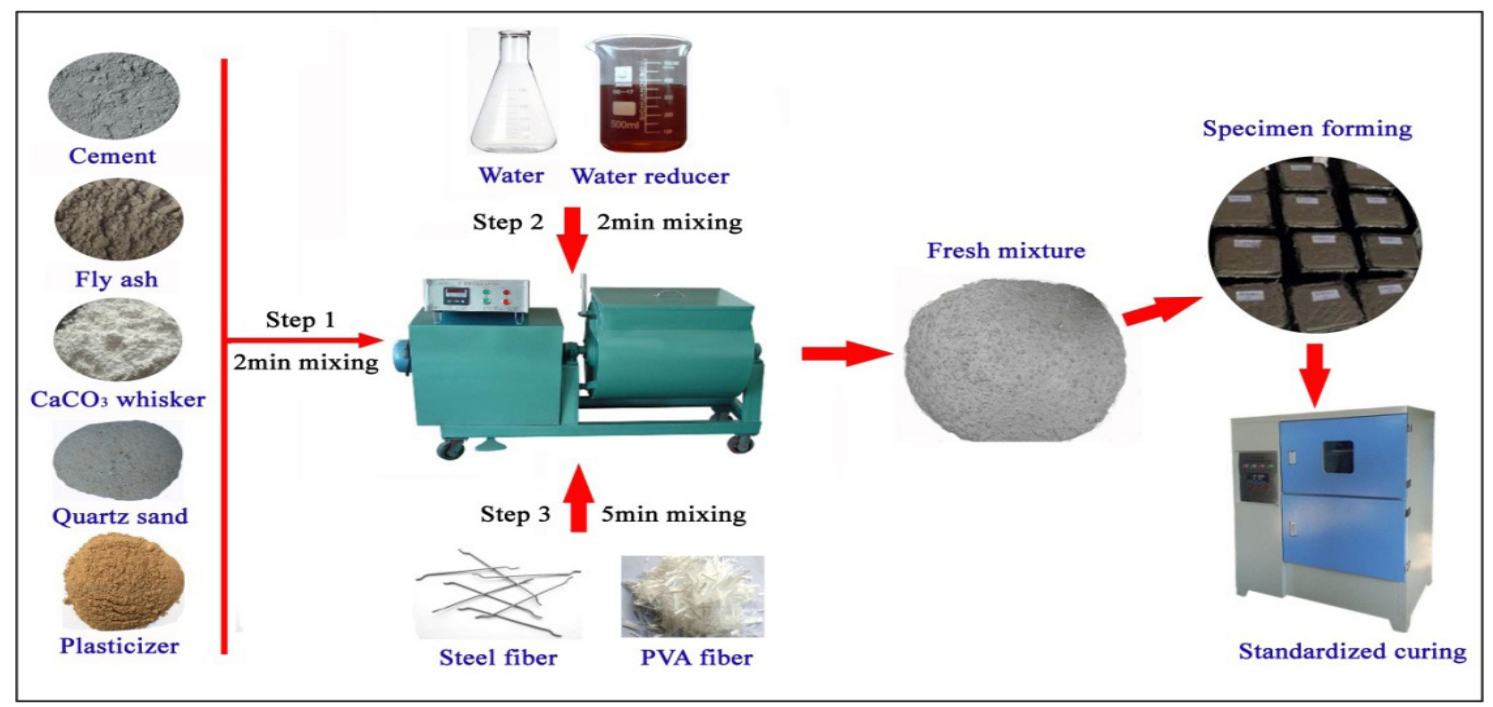

Figure 1 Preparation process of specimens

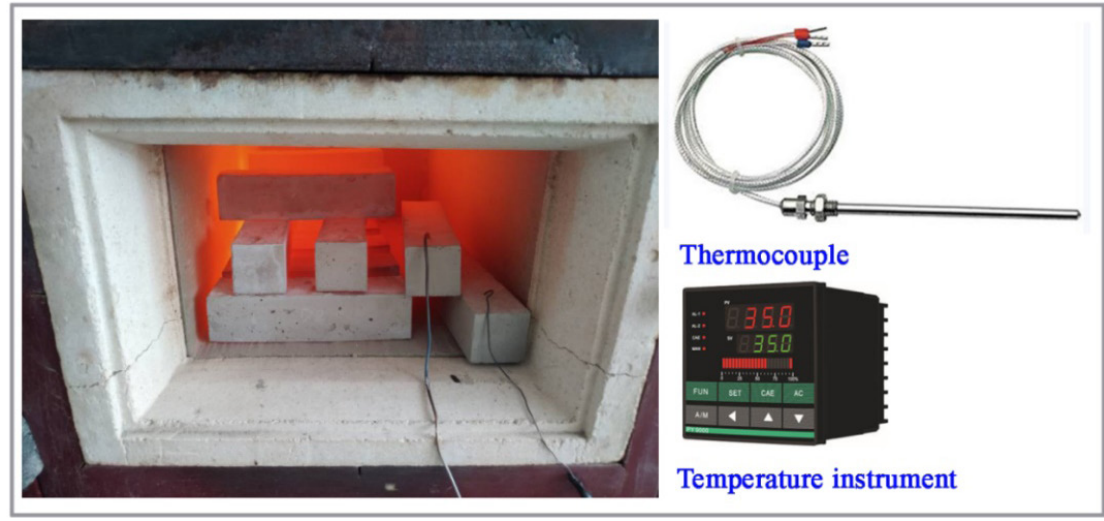

Figure 2 Instrument for high temperature test 


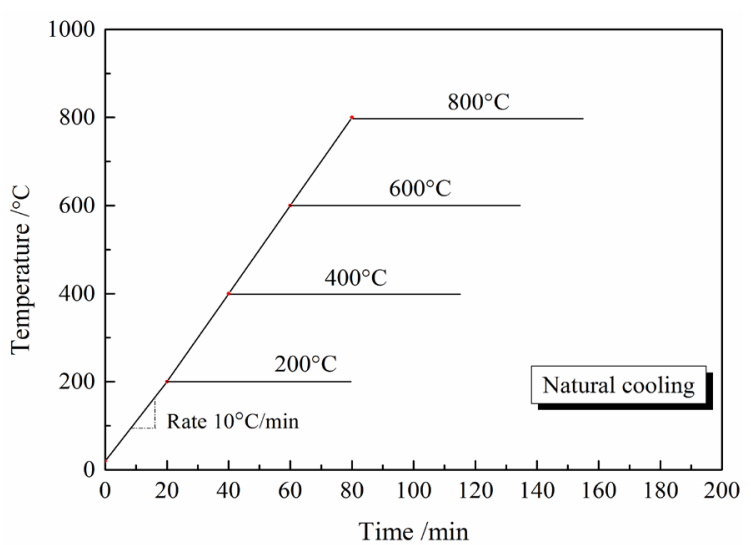

Figure 3 Heating Program for high temperature test

\section{Experimental Results and Discussion}

\subsection{Appearance color change}

Figure 5 shows the appearance color of PVA-ECC and HyFRECC-B specimens after natural cooling changes with the temperature experienced. It can be observed from figure 5 that the appearance color of all specimens is dark grey at room temperature, and the color of the specimen gradually fades to light brown with the increase in experienced temperature, that is no difference in the rule of color change of ordinary cement mortar and concrete at high temperature. With the increase in temperature, there are also the processes of evaporation of free water $\left(30 \sim 105^{\circ} \mathrm{C}\right)$, decomposition of gypsum and ettringite $\left(110 \sim 170^{\circ} \mathrm{C}\right)$, decomposition of calcium silicate hydrate, loss of binding water $\left(180 \sim 300^{\circ} \mathrm{C}\right)$, mass decomposition of calcium silicate hydrate and calcium

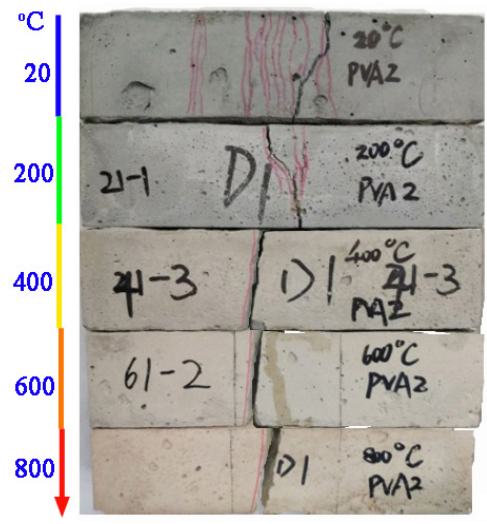

(a) PVA2
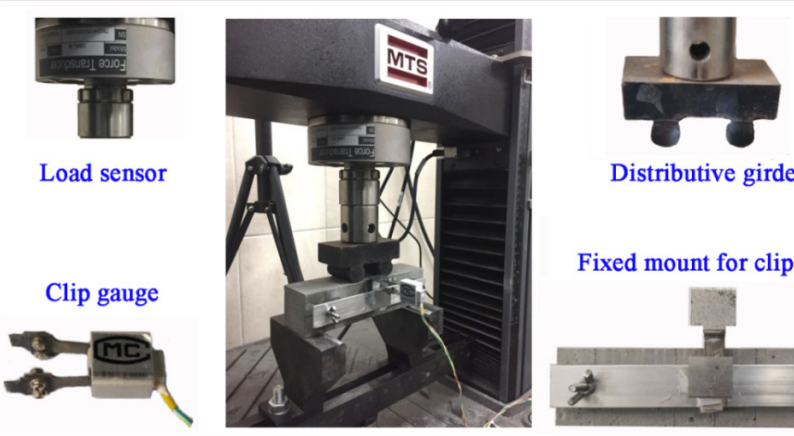

Distributive girder

Fixed mount for clip gauge

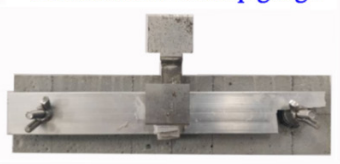

Figure 4 Loading instrument for flexural test

hydroxide $\left(450 \sim 550^{\circ} \mathrm{C}\right)$, and decomposition of calcium carbonate $\left(700 \sim 900^{\circ} \mathrm{C}\right)$ in PVA-ECC and HyFRECC-B specimens ${ }^{[26]}$. It is worth mentioning that since $400^{\circ} \mathrm{C}$, the appearance color of specimens changed apparently which indicates the water loss process has basically ended, and the cement hydration products begin to decompose in large quantities. This process is very unfavorable to steel fiber and calcium carbonate whiskers due to the decomposition of calcium silicate hydrate will weaken the interfacial bond between the fiber and the matrix. In addition, the specimens of PVA-ECC and HYFRECC-B did not burst at high temperature, indicating that PVA fiber could restrain or alleviate the burst behavior of cement matrix composite at high temperature, as a consequence PVA fiber would melt at about $250{ }^{\circ} \mathrm{C}$ result in increasing the release channel of steam pressure inside the material ${ }^{[27]}$.

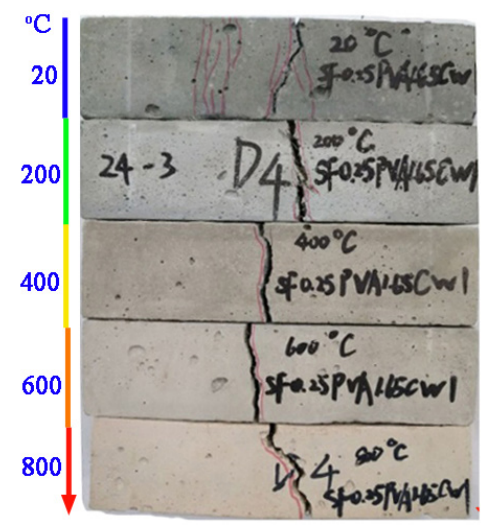

(b) SF0.25PVA1.65CW1

Figure 5 Effect of temperature on the color change of specimen

\subsection{Load-deflection relationships}

Three specimens were tested at room temperature for each mix proportion, and the median value of the flexural load-midspan deflection relationship is taken as the representative curve as seen in figure 6. It can be observed from figure $6 \mathrm{a}$ that the flexural specimens of PVA2 group showed obvious characteristics of deflection hardening. However, compared with PVA2 group, the deflection hardening ability of SF0.25PVA1.75 (equivalent substituting PVA fiber with $0.25 \%$ steel fiber) specimens was significantly weakened. With the incorporation of $\mathrm{CaCO}_{3}$ whisker (SF0.25PVA1.7CW0.5 and SF0.25PVA1.65CW1), compared with SF0.25PVA1.75 group, the flexural deflection hardening ability of specimens was significantly enhanced, although the ultimate deflection value was still lower than PVA2 group, the peak flexural load of 
the specimen was significantly higher than PVA2 group, which further demonstrated the feasibility of replacing the relatively expensive PVA fiber with cheap $\mathrm{CaCO}_{3}$ whisker. What's more, as shown in figure $6 \mathrm{~b}$, the initial crack of each specimen occurred at a deflection of $25 \mu \mathrm{m}$, and due to the addition of $\mathrm{CaCO}_{3}$ whisker, its micro-crack resistance can make great contributions to increasing the initial crack load of specimens ${ }^{[19]}$.

Three specimens subjected to the temperature of $200^{\circ} \mathrm{C}$ were tested for each mix proportion, and the median value of the flexural load-midspan deflection relationship is taken as the representative curve as seen in figure 7. As shown in figure 7a, the specimens of PVA-ECC, HyFRECC-A and HyFRECC-B had basically lost the deflection hardening behavior after the temperature of $200^{\circ} \mathrm{C}$, reflecting that PVA fiber plays a decisive role in the flexural deflection hardening behavior. Considering the fact that PVA fiber would soften significantly under the temperature of $200^{\circ} \mathrm{C}$, which will destroy the interface bond between PVA fiber and cement matrix, and degrade the flexural deflection hardening behavior of specimens. In addition, the specimens in each group still retained a small amount of deflection hardening behavior, because the softened PVA fibers recovered some of their mechanical properties after natural cooling. Compared with PVA2 and SF0.25PVA1.75 groups, the addition of $\mathrm{CaCO}_{3}$ whisker did not significantly

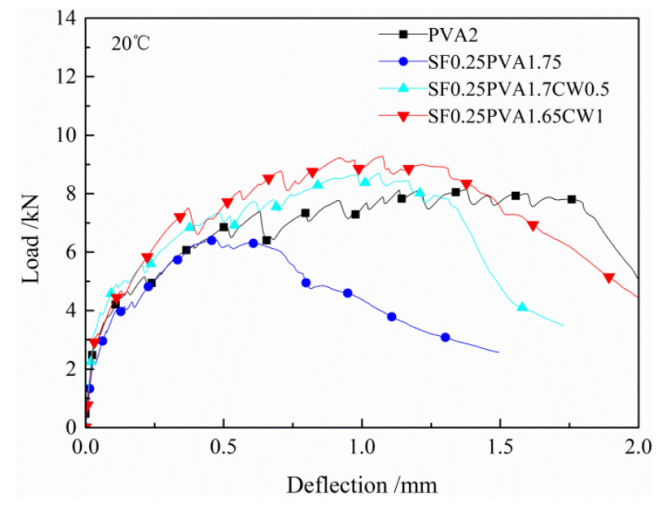

(a) $2 \mathrm{~mm}$ of deflection improve the flexural deflection hardening behavior of specimens but improved the flexural load of specimens with fuller post-peak curve, reflecting that the whisker is still beneficial to the toughness of the specimen. It can be observed from figure $7 \mathrm{~b}$, the initial crack of each specimen occurred at a deflection of $40 \mu \mathrm{m}$, and the first cracking load of specimen was improved due to the addition of whisker.

Figure 8, 9 and10 show the typical flexural loaddeflection relationships of tested specimen subjected to the temperature of $400{ }^{\circ} \mathrm{C}, 600{ }^{\circ} \mathrm{C}, 800{ }^{\circ} \mathrm{C}$ respectively. It could be concluded by comparison that, when the temperature exceeds $400{ }^{\circ} \mathrm{C}$, all specimens in each group have completely lost the flexural deflection hardening behavior and changed into obvious softening characteristics. The reason lies in that the PVA fiber began to melt and decompose at about $250{ }^{\circ} \mathrm{C}$, which caused the PVA2 group specimens degraded into ordinary cement mortar specimens, showing obvious brittle failure behavior. In addition, it can be found that the peak flexural load of each group gradually decreases with the increase of temperature. The specimens of HyFRECC-A and HyFRECC-B subjected to the temperature of $400{ }^{\circ} \mathrm{C}$, $600{ }^{\circ} \mathrm{C}$ and $800{ }^{\circ} \mathrm{C}$ still had high load carrying capacity due to end hooks of steel fiber employed in the experiment. It can be found that the whisker, whose decomposition temperature is about $780{ }^{\circ} \mathrm{C}$, is still beneficial to improve the post-peak carrying capacity of the HyFRECC-B specimen

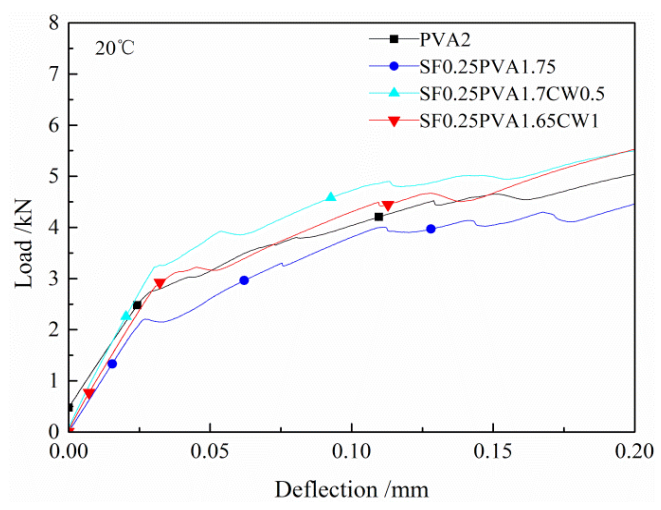

(b) $0.2 \mathrm{~mm}$ of deflection

Figure 6 Flexural load-deflection curve of tested specimen at room temperature

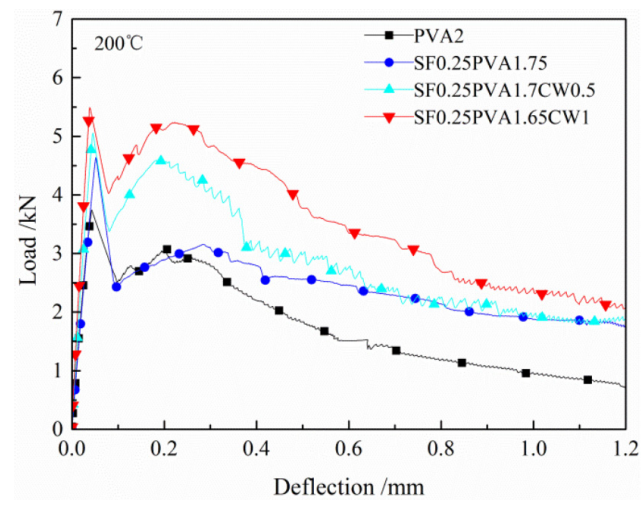

(a) $1.2 \mathrm{~mm}$ of deflection

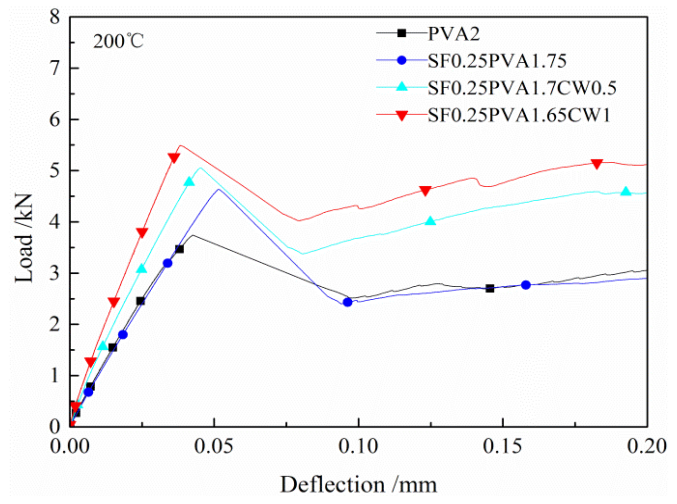

(b) $0.2 \mathrm{~mm}$ of deflection

Figure 7 Flexural load-deflection curve of tested specimen after $200^{\circ} \mathrm{C}$ 
after the temperature of $400{ }^{\circ} \mathrm{C}$ and $600{ }^{\circ} \mathrm{C}$, and the carrying capacity tends to be further improved with the increase of whisker content, reflecting the superiority of the whisker properties. However, it can be observed from figure 10 that at $800{ }^{\circ} \mathrm{C}$, the effect of whisker on the post-peak bearing capacity basically disappeared, and there was no obvious difference in the flexural load-deflection relationships between HyFRECC-A and HyFRECC-B specimens. By comparing figure $8 \mathrm{~b}, 9 \mathrm{~b}$ and $10 \mathrm{~b}$, it can be found that due to the high-temperature deterioration of cement matrix, the initial crack deflection of each specimen increases with the increase of temperature. Compared with HyFRECC-A, the addition of $\mathrm{CaCO}_{3}$ whisker improved the initial crack load and deflection of ECC materials, while the function of whiskers is no longer obvious after $800{ }^{\circ} \mathrm{C}$.

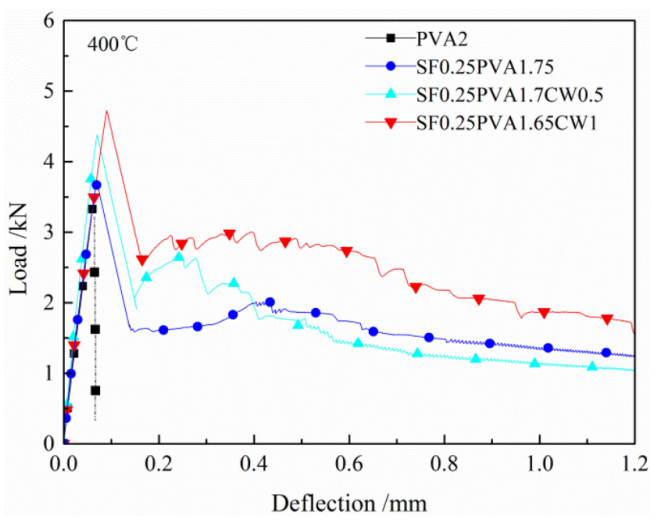

(a) $1.2 \mathrm{~mm}$ of deflection

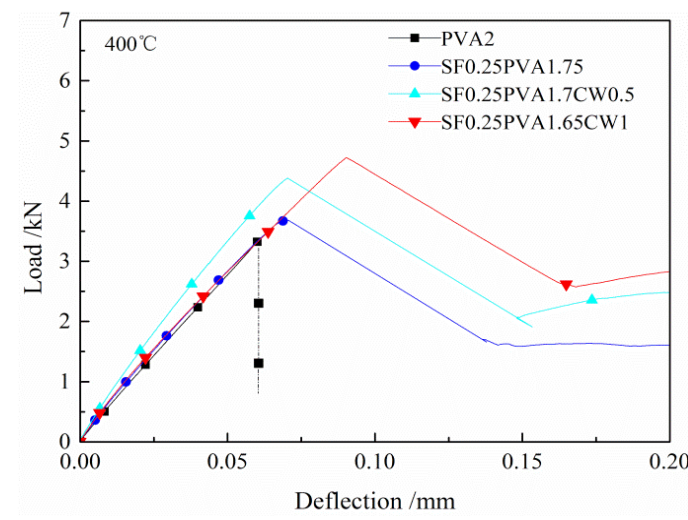

(b) $0.2 \mathrm{~mm}$ of deflection

Figure 8 Flexural load-deflection curve of tested specimen after $400{ }^{\circ} \mathrm{C}$

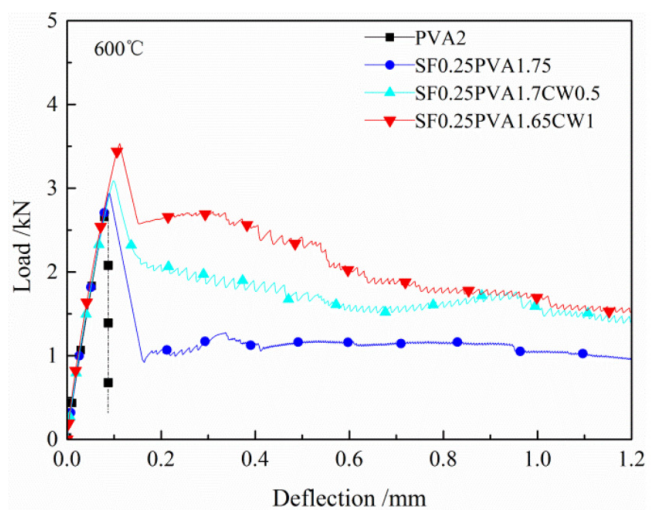

(a) $1.2 \mathrm{~mm}$ of deflection

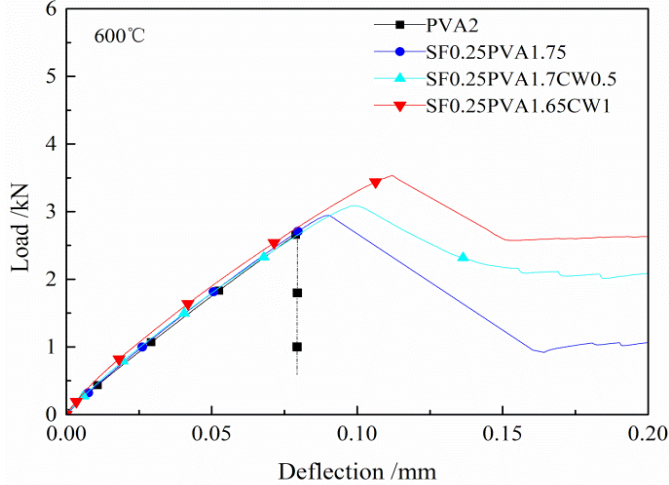

(b) $0.2 \mathrm{~mm}$ of deflection

Figure 9 Flexural load-deflection curve of tested specimen after $600{ }^{\circ} \mathrm{C}$

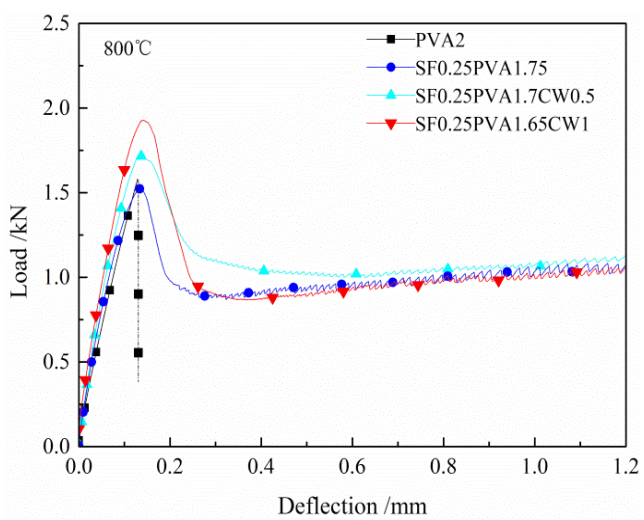

(a) $1.2 \mathrm{~mm}$ of deflection

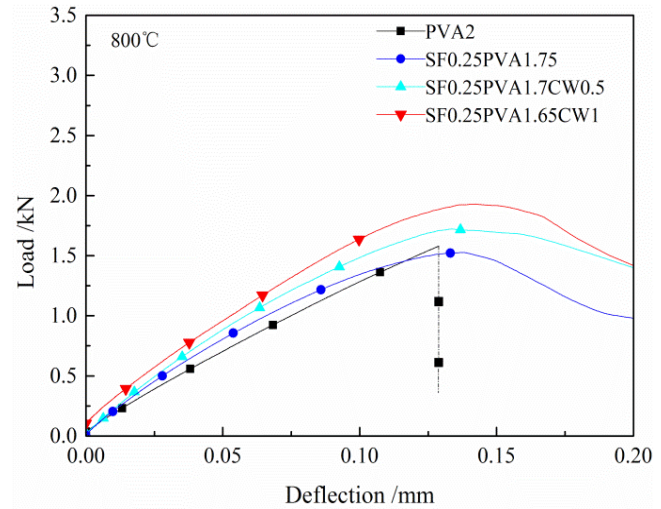

(b) $0.2 \mathrm{~mm}$ of deflection

Figure 10 Flexural load-deflection curve of tested specimen after $800{ }^{\circ} \mathrm{C}$ 


\subsection{Flexural strength}

Figure 11a plots the relationship between flexural strength and temperature of each group. The flexural strength of each specimen decreases significantly with the increase of temperature. At the same temperature, the flexural strength of HyFRECC-A was higher than that of PVAECC, and the incorporation of $\mathrm{CaCO}_{3}$ whisker can further improve the flexural strength of specimens subjected to various temperatures. The relationship between the flexural strength of PVA2 group specimens and temperature as shown in figure $11 \mathrm{~b}$. The flexural strength of the specimen decreases exponentially with temperature in a situation where only PVA fiber is employed, and after $200{ }^{\circ} \mathrm{C}$, the flexural strength of the specimen decreased by nearly $50 \%$, while after $800{ }^{\circ} \mathrm{C}$, the flexural strength of the specimen was less than $20 \%$ of the normal temperature, reflecting that the high temperature has a significant deterioration effect on the flexural strength of PVA-ECC. The relationship between the flexural strength of SF0.25PVA1.75 group specimens and temperature as shown in figure 11c. The flexural strength of the specimen decayed linearly with temperature due to steel fiber employed in the test. Compared with the PVA2 group, the flexural strength decayed more slowly. After 200 ${ }^{\circ} \mathrm{C}$ the flexural strength of the specimen decreased by $25 \%$, and after $800{ }^{\circ} \mathrm{C}$, the flexural strength of the specimen was about $23 \%$ of that at room temperature, indicating that the end hooks shaped steel fiber had a significant improvement

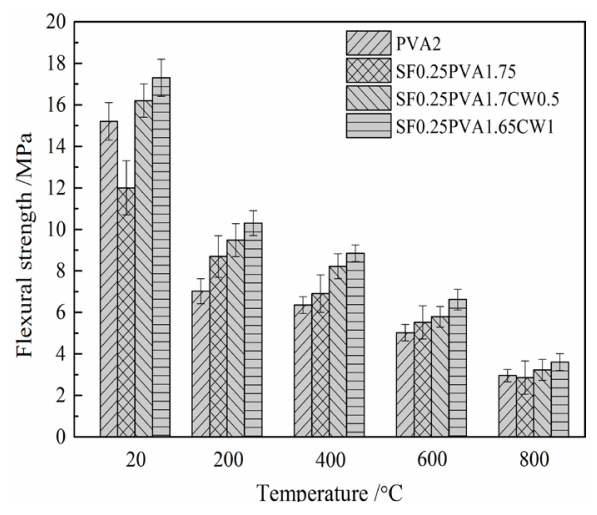

(a) Flexural strength

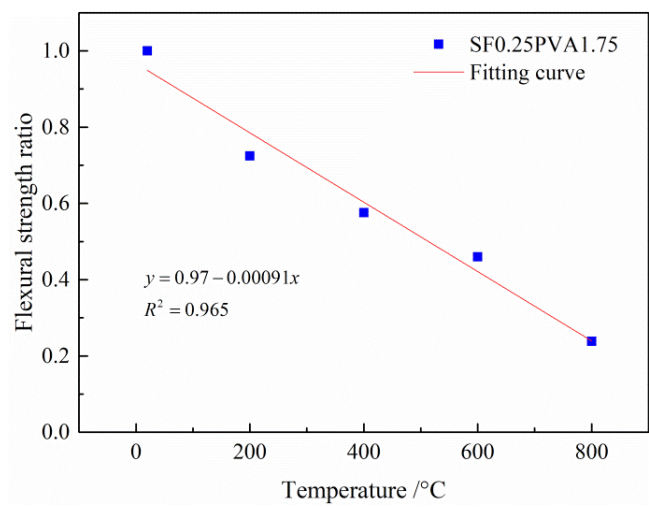

(c) SF0.25PVA1.75 on the flexural strength of the specimen after high temperature. The relationship between the flexural strength of HyFRECC-B group specimens mixed with $\mathrm{CaCO}_{3}$ whisker and temperature as shown in figure $11 \mathrm{~d}$. It can be found that the attenuation tendency of flexural strength with temperature keeps basically consistent between SF0.25PVA1.7CW0.5 and SF0.25PVA1.65CW1 group, while the attenuation tendency of SF0.25PVA1.7CW0.5 group is different from that of SF0.25PVA1.75 significantly. Compared with HyFRECC-A, the attenuation of flexural strength of HyFRECC-B is more obvious between 200 ${ }^{\circ} \mathrm{C}$ and $400{ }^{\circ} \mathrm{C}$. The reason lies in that after $180{ }^{\circ} \mathrm{C}$, calcium silicate hydrate begins to decompose, which weakens the interface bond between whisker and cement matrix and reduces the bridging effect of whisker, which is an important mechanism for whisker to exert its reinforcing effect ${ }^{[28]}$. Moreover, by comparing figure $11 \mathrm{c}$ with figure $11 \mathrm{~d}$, it can be found that despite the fact that $\mathrm{CaCO}_{3}$ whiskers can improve the flexural strength of specimens after $400{ }^{\circ} \mathrm{C}$, they have little significant influence on the attenuation rate of flexural strength with temperature.

\subsection{Flexural toughness}

Toughness reflects the ability of material to absorb energy and undergo plastic deformation before fracture. The flexural toughness of each group is obtained by integrating the load-deflection curve, which is calculated to $\mathrm{L} / 100$

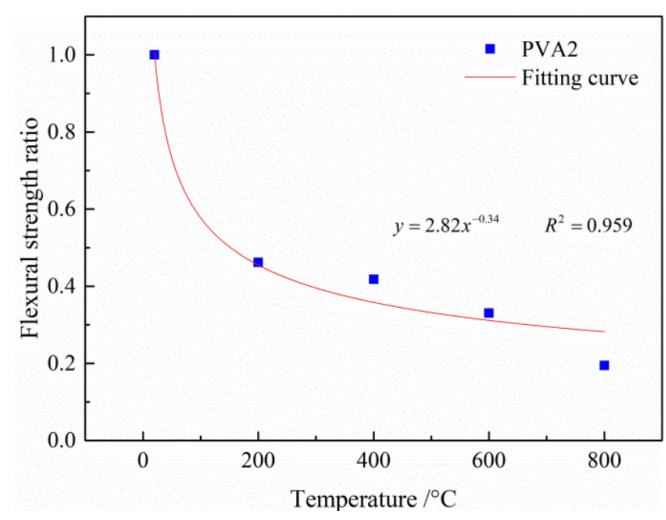

(b) PVA2

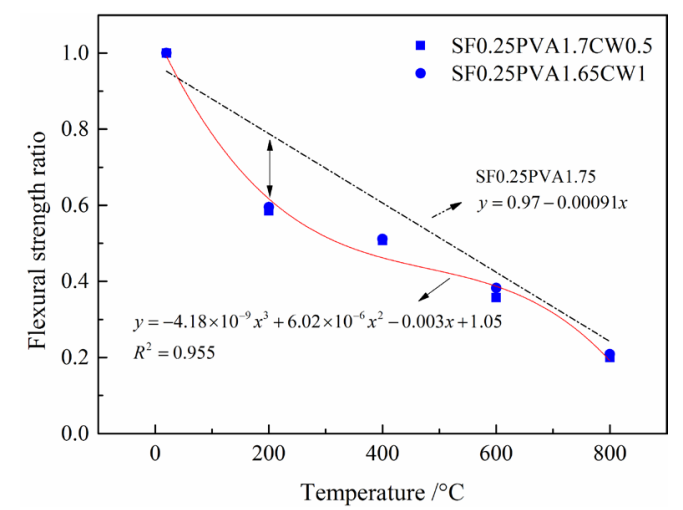

(d) SF0.25PVA1.7CW0.5 and SF0.25PVA1.65CW1

Figure 11 Effect of temperature on (a) flexural strength and (b) $\sim(d)$ flexural strength ratio 
(referred to ASTM C1609 ${ }^{[24]}$ ), i.e., the deflection of $1.2 \mathrm{~mm}$. Figure 12a shows the relationship between the flexural toughness of each group of specimens and temperature. With the increase of temperature, the flexural toughness of each sample decreased obviously. At normal temperature, the flexural toughness of PVA2 group was significantly higher than that of SF0.25PVA1.75 group, reflecting that the use of steel fiber to substitute PVA fiber equivalently degraded flexural energy absorption capacity of ECC materials, while the addition of $\mathrm{CaCO}_{3}$ whisker further improves the flexural toughness of ECC. Since whisker can improve the microstructure and fracture morphology of cement matrix by means of microcosmic effect such as crack deflection, bridging and whisker pull-out, the flexural deflection hardening and multi-crack cracking ability of steel fiber /PVA fiber HyFRECC-A material can be improved. In addition, it can be seen that when the temperature exceeds $400{ }^{\circ} \mathrm{C}$, PVA2 materials are not significantly different from ordinary cement mortar, and the flexural toughness value is only about 0.1J. At the same temperature, the flexural toughness of HyFRECC-A is higher than that of PVA-ECC, and the introduction of $\mathrm{CaCO}_{3}$ whisker can further improve the flexural toughness of specimens subjected to different high temperatures.

The flexural toughness value of each group of specimens at room temperature was taken as unit 1 , and the comparison of the flexural toughness value at high

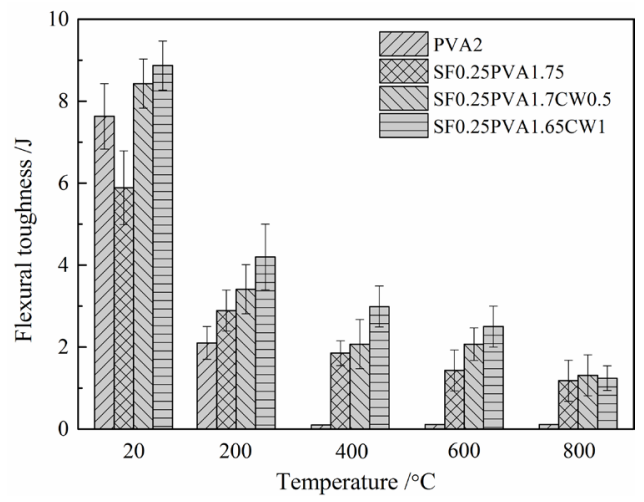

(a) Flexural toughness temperature was defined as the flexural toughness ratio. Figure 12b plots the relationship between the flexural toughness ratio of PVA2 specimens and temperature. The flexural toughness ratio of PVA2 group specimen decays exponentially with the increase of temperature. At $200{ }^{\circ} \mathrm{C}$, the material's energy absorption capacity was less than $30 \%$ of the normal temperature, and after $400{ }^{\circ} \mathrm{C}$, it was only about $1 \%$ of the normal temperature, proving that PVAECC could not service normally under high temperature environment. It can be concluded from figure $12 \mathrm{c}$ that the incorporation of steel fiber reduces the attenuation rate of flexural toughness. The flexural toughness of HyFRECC-A decays about $50 \%$ after $200{ }^{\circ} \mathrm{C}$, while at $800{ }^{\circ} \mathrm{C}$, the flexural energy absorption capacity of HyFRECC-A remained $20 \%$ compared with normal temperature. The relationship between the flexural toughness ratio of HyFRECC-B group specimens mixed with $\mathrm{CaCO}_{3}$ whisker and temperature as shown in figure 12d. Compared with HyFRECC-A group (see figure 12c), it can be observed that the whisker failed to further retard the attenuation rate of the flexural toughness of the specimen, but only increased the flexural toughness of the specimen under various temperature conditions. The reason lies in that the bonding ability between whisker and cement matrix decreases with the increase of temperature, however, the toughening mechanism of whisker such as crack deflection and pull out is beneficial to improve the energy absorption capacity of ECC material ${ }^{[28]}$.

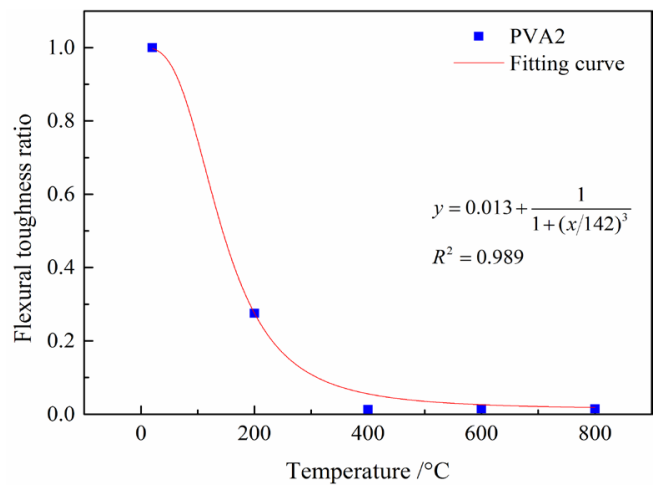

(b) PVA2

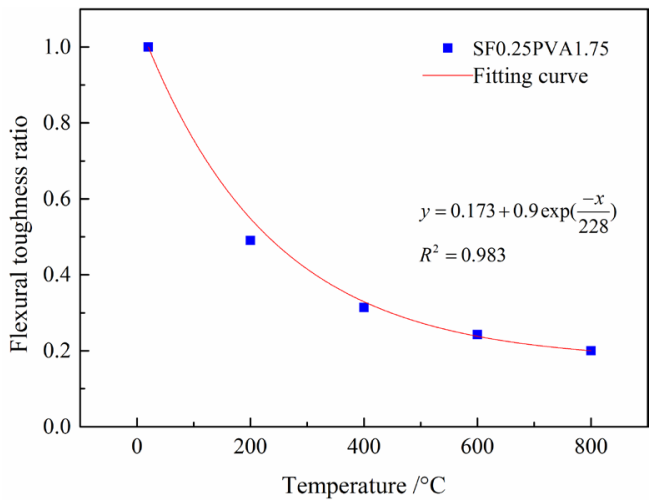

(c) SF0.25PVA1.75

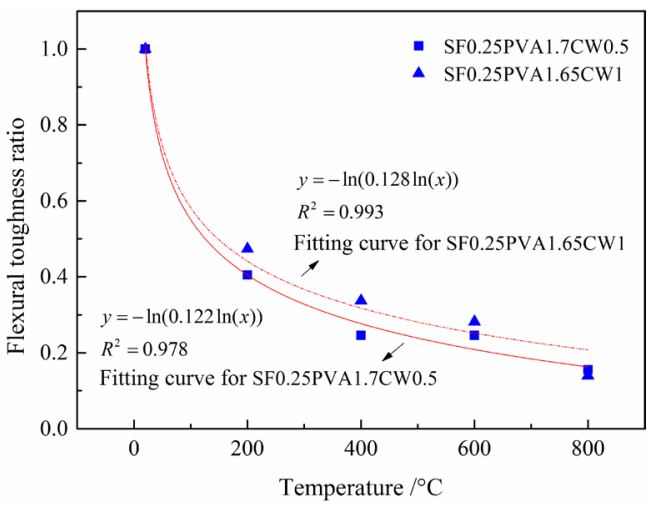

(d) SF0.25PVA1.7CW0.5 and SF0.25PVA1.65CW1

Figure 12 Effect of temperature on (a) flexural toughness and (b) (d) flexural toughness ratio 


\section{Conclusion}

In this paper, the effects of temperature on flexural performance in terms of flexural strength, flexural toughness of PVA-ECC, HyFRECC-A and HyFRECC-B were analyzed, demonstrating the feasibility of using calcium carbonate whisker to partially replace PVA fiber to reduce the cost of ECC materials. The following conclusions can be drawn:

At room temperature, the flexural deflection harden ability of PVA-ECC is degraded by replacing PVA fiber with steel fiber, while it can improve the flexural strength, flexural toughness and deflection hardening ability in a situation where calcium carbonate whisker replaces PVA fiber. It is feasible to reduce the cost of PVA-ECC and steel fiber /PVA fiber HyFRECC-A by replacing PVA fiber with calcium carbonate whisker moderately.

Rather significant is the effect of high temperature action on the flexural strength of PVA-ECC, HyFRECC-A and HyFRECC-B specimens. After $200{ }^{\circ} \mathrm{C}$ exposure, all the materials in each group had lost the flexural deflection hardening ability basically, while after $400{ }^{\circ} \mathrm{C}$, they had completely lost the flexural deflection hardening behavior and changed into obvious softening characteristics.

The flexural strength and toughness of PVA-ECC decrease exponentially with the increase of temperature,but the incorporation of steel fiber can slow down the attenuation rate of the flexural strength and toughness of specimens. Despite the fact that calcium carbonate whiskers can improve the flexural strength and flexural toughness of materials under high temperature, they are useless to slow down the attenuation rate of flexural strength and flexural toughness with temperature.

Author Contributions: Zhihui YU performed the experiment and wrote this manuscript; Zhen YUAN contributed significantly to manuscript preparation; Chaofan XIA performed the data analyses; Cong ZHANG helped perform the analysis with constructive discussions, he will be responsible for this article.

Conflict of Interest: The authors declare that they have no known competing financial interests or personal relationships that could have appeared to influence the work reported in this paper.

Acknowledgments: This study was supported by the National Natural Science Foundation of China (51908247), Jiangsu Natural Science Foundation Project (BK20170192) and Open Fund Project of State Key Laboratory of Green Building Materials (YA-616).

\section{References}

[1] Li VC. Progress and application of Engineered Cementitious Composites [J]. Journal of the Chinese Ceramic Society, 2007, 35(4): 531-536.

[2] Li VC. On Engineered Cementitious Composites (ECC) [J]. Journal of Advanced Concrete Technology, 2003, 1(3): 215-230.
[3] LIU Zejun, LI Yan, WEN Congge. Experimental study on strength and deformation performance of PVA-ECC under splitting tension [J]. Journal of Building Materials, 2016, 19(4): 746-751.

[4] Qudah S, Maalej M. Application of Engineered Cementitious Composites (ECC) in interior beamecolumn connections for enhanced seismic resistance [J]. Engineering Structures, 2014, 69: 235-245.

[5] Choi W, Yun H, Cho C. Attempts to apply high performance fiber-reinforced cement composite (HPFRCC) to infrastructures in South Korea [J]. Composite Structures, 2014, 109: 211-223.

[6] WANG Zhenbo, ZHANG Jun, WANG Qing. Mechanical behavior and crack width control of hybrid fiber reinforced ductile cementitious composites [J]. Journal of Building Materials, 2018, 21(2): 216-221.

[7] Maalej M, Quek ST, Ahmed SFU, et al. Review of potential structural applications of hybrid fiber Engineered Cementitious Composites [J]. Construction and Building Materials, 2012, 36: 216-227.

[8] WANG Zhenbo, ZUO Jianping, ZHANG Jun. Mechanical properties of hybrid fiber reinforced Engineered Cementitious Composites under uniaxial compression [J]. Journal of Building Materials, 2018, 21(4): 639-644.

[9] Khin TS, Zhang YX, Zhang LC. Material properties of a new hybrid fibre-reinforced Engineered Cementitious Composites [J]. Construction and Building Materials, 2013, 43: 399-407.

[10] Khin TS, Zhang YX, Zhang LC. Impact resistance of hybridfibre Engineered Cementitious Composite panels [J]. Composite Structures, 2013, 104: 320-330.

[11] Alessandro PF, Hirozo M, Tomoya N. Tailoring hybrid strain-hardening cementitious compsotes $[\mathrm{J}]$. ACl Materials Journal, 2014, March-April: 211-218.

[12] Jun Zhang, Zhenbo Wang, Qing Wang. Simulation and test of flexural performance of polyvinyl alcohol-steel hybrid fiber reinforced cementitious composite [J]. Journal of Composite Materials, 2016, 0: 1-15.

[13] Li QH, Gao X, Xu SL. Multiple effects of nano-SiO2 and hybrid fibers on properties of high toughness fiber reinforced cementitious composites with high volume fly ash [J]. Cement and Concrete Composites, 2016, 72: 201-212.

[14] Sahmaran M, Lachemi M, Li VC. Assessing mechanical properties and microstructure of fire-damaged Engineered Cementitious Composites [J]. ACI Materials Journal, 2010, 107(3): 1-8.

[15] Sahmaran M, Lachemi M, Li VC. Effect of fly ash and PVA fiber on microstructural damage and residual properties of Engineered Cementitious Composites exposed to high temperatures [J]. ASCE Journal of Materials in Civil Engineering, 2011, 23(12): 1735-1745.

[16] Mechtcherine V, Andrade S, Muller S. Coupled strain 
rate and temperature effects on the tensile behavior of strain-hardening cement-based composites (ECC) with PVA fibers [J]. Cement and Concrete Research, 2012, 42(11): 1417-1427.

[17] Bhat PS, Chang V, Li M. Effect of elevated temperature on strain-hardening engineered cementitious composites [J]. Construction and Building Materials, 2014, 69: 370380.

[18] Magalhaes M, Toledo Filho R, Fairbairn E. Thermal stableility of PVA fiber strain hardening cement-based composites [J]. Construction and Building Materials, 2015, 94: 437-447.

[19] ZHANG Cong, CAO Ming-li. Mechanical property test of a multi-scale fiber reinforced cementitious composites [J]. Acta Materiae Composite Sinica, 2014, 31(3): 661-668.

[20] Ma H, Cai JM, Lin Z. $\mathrm{CaCO}_{3}$ whisker modified Engineered Cementitious Composite with local ingredients [J]. Construction and Building Materials, 2017, 151: 1-8.

[21] ZHANG Cong, CAO Ming-li. Using calcium carbonate whisker in hybrid fiber reinforced cementitious composites [J]. ASCE Journal of Materials in Civil Engineering, 2015, 27(4): 1-13.

[22] International Organization for Standardization. ISO 679 Cement-Test methods-Determination of strength [S].
Switzerland: ISO, 2009.

[23] American Society for Testing and Materials. ASTM C348 Standard test method for flexural strength of hydrauliccement mortars [S]. Philadelphia: ASTM International, 2008.

[24] American Society for Testing and Materials. ASTM C1609 Standard test method for flexural performance of fiber-reinforced concrete [S]. Philadelphia: ASTM International, 2010

[25] Japan Concrete Institute. JCI-SF4 Methods of tests for flexural strength and flexural toughness of fiber reinforced concrete [S]. Japan: Japan Concrete Institute, 1983.

[26] Lucia A, Gerard P, Etienne M. The use of thermal analysis in assessing the effect of temperature on a cement paste [J]. Cement and Concrete Research, 2005, 35: 609-613.

[27] Liu JC, Tan KH. Mechanism of PVA fiber in mitigating explosive spalling of engineered cementitious composite at elevated temperature [J]. Cement and Concrete Composites, 2018, 93: 235-245.

[28] ZHANG Cong, CAO Ming-li. Microscopic reinforcement for cement based composite materials [J]. Construction and Building Materials, 2013, 40: 14-25. 